\section{UNIVERSITY AND EDUCATIONAL.}

\section{INTELLIGENCE}

CAMBRIDGE, May 30.-The Sheepshanks Astronomical Exhibition has been adjudged to John Edward Aloysius Steggall, scholar of Trinity College.

The twenty-second annual report of the Botanic Garden Syndicate has been issued. It is stated that during the past year much attention has been paid to the labelling of the arranged trees, shrubs, and herbaceous plants in the open ground, and it is believed that they all, or nearly all, are correctiy and legibly named. There has not been time, without neglecting other important work, to name with similar completeness the plants scattered in the belt. It is believed that very few of the plants in the houses are without names, although a few duplicate specimens may be in that condition. About 1,700 new labels have been written. The culture of the plants is such as to give satisfaction to the syndicate. About r jo species of herbaceous plants have been raised from seed to supply the places of those which have died. Among the presents acknowledged are packets of seeds from the Indian Botanic Gardens, from Baron F. v. Mueller, and five large ferns from Australia from the last-mentioned gentleman.

OXFORD. - At the ensuing commemoration the honorary degree of D.C.L. will be conferred upon Mr. J. Evans, the distinguished antiquary; Di. Harold Browne, the Bishop of Winchester; and Lord Coleridge. It is probable that degrees will be conferred on certain other distinguished persons, whose names, however, it would be premature to announce at present.

On November 23 next there will be an election to a Brackenbury Natural Science Scholarsnip at Balliol College, worth 8ol. a year, tenable during residence for four years, open to all such candiciates as shall not have exceeded eight terms from matrica. lation. Papers will be set in (I) Mechanical Philosophy and Physics, (2) Chemistry, (3) Physiology; but candidates will not ve expected to offer in more than two of these.

DUSHAM. - The University Mathematical Scholarship has been awarded to Mr. F. W. Sanderson, Hatfield Hall.

THs. UinIVERsix les BHL. - The attempt was made iwice on Nonday in the House of Commons to get a clause inserted in the Universities Bill abolishing Clerical Fellowships. As might have been expected, the attempt failed, though in the case of Mr. Goschen's motion by a very narrow majority-only 9 .

UNIVERSTTES AND NATIONAL LIFE. - The following forcible remarks on universities and national life occur in the address of Prof. Sylvester at the Johns Hopkins University, to which we have already referred:-" The mention of Germany brings to my mind the importance of universities to the maintenance or development of a national spirit in the countries in which they are fostered and carried on with an animus free from local or sectarian prejudices. I think that there can be little doubt that the greatest fact in modern history, the consolidation of the German empire, the resurrection of the German people, is mainly to be attributed to the feeling of brotherhood and the spirit of nationality kept alive in those ganglions of thought, those centres of intellectual activity, the German universities. It is the university professors who have made German unity a possibility, and I cannot but deplore the unpatriotic short-sightedness of those in my own country who, until so late a period, have struggled, and still covertiy struggle, to make our universities in England not the representatives of the universal English mind, but the monopoly of a party and the appanage of a sect."

\section{SCIENTIFIC SERIALS}

American Fournal of Science and Arts, May.-On vortex rings in liquids, by J. Trowbridge.-An account of the discoveries in Vermont Geology of the Rev. Augustus Wing, by J. D. Dana.- Notes on the history of Helianthus tuberosus, the so-called Jerusalem artichoke, by J. H. Trumbull and Asa Gray. - A new investigation of one of the laws of friction, by A. S. Kimball.-Examination of American columbic acid minerals, by I. Lawrence Smitb. - On the sensitiveness to light of various salts of silver, by M. Carey Lea.

Posgendorff's Annalen der Physik und Chemie, No. 3.-On the cohesion of salt solutions, by G. Quincke.-On the theory of stationary electric flow in curved surfaces, by A. Topler.-On normal magnetisation, by $M$. Petruscheffsky...-On the tempe. rature in the conducting wire of a galvanic current, by $M$. Streintz. - Remarks on a statement of $\hat{F}$. Kohlrausch on therrioelectricity, by M. Clausius, - On the galvanic resistance of haloid compounds, by M. Lenz.--On the dynamical significance of the quantities occurring in the mecbanical theory of heat, by $M$. Szily.-On a paradox of the mechanical theory of heat, by $M$. Ritter.-Researches on the movements of radiating and irradi. ated bodies (concluded), by $M$. Zöllner,-On the connection between absorption and dispersion, by M. Ketteler.-On the neutral combs of the Holtz machine, by M. Riess.-Galvanic dipping battery for elements with two liquids, by M. Hert $z$.

Reale Istituto Lombardo di Scienze e Lettere. Rendiconti, vol. x. fasc. iv. v. vi. - Observations on Borrelly's comet, by M. Schiaparelli.-Ditto by P. Secchi. - On a singular congenital and lipomatous pigmeritary alteration, by M. Scarenzio.-Contribution to the study of Addison's disease, by M. Vals:ani, - New barometric formula for the measurement of altitudes, and the reduction of barometric heights to the sea-level, by M. GrassiGeneral method of obtaining diagrams of the motion of a point, by $M$. Padelletti. - On algebraic differential equations of the first order and first degree, by M. Pincherle. - On some questions of electrostatics, by $M$. Beltrami. - On some unpublished letters from Lagrange to Kuler, by $M$. Schiaparelli, - Origin and anatomy of intestinal diverticula, and their application in practical surgery, by M. Sangalli.-On a new species of Dochmius (Dochmius balsami), by MM. Parona and Cirassi.

\section{SOCIETIES AND ACADEMIES LONDON}

Royal Society, May 31.- "On the Amplitude of Sound. Waves," by Lord Rayleigh, M.A., F.R.S.

Scarcely any attempts have been made, so far as I am aware, to measure the actual amplitude of sound-bearing waves, and indeed the problem is one of considerable difficulty. Even if the measurement could be effected, the result would bave reference only to the waves actually experimented upon, and would be of no great value in the absence of some means of defining the intensity of the corresponding sound. It is bad policy, however, to despise quantitative estimates because they are rough, and in the present case it is for many reasons desirable to have a general idea of the magnitudes of the quantities with which we have to deal. Now it is evident that a superior limit to the amplitude of waves giving an audible sound may be arrived at from a knowledge of the energy which must be expended in a given time in order to generate them, and of the extent of surface over which the waves so generated are spread at the time of hearing. Anl estimate founded on these data will necessarily be too hirgh, both because sound-waves must suffer some dissipation in their progress, and also becalse a part, and in some cases a large part, of the energy expended never takes the form of sound-waves at all.

The source of sound in my experiment was a whistle, mounted on a Wolf's bottle, in conneztion with which was a syphon manometer, for the purpose of measuring the pressure of wind. This apparatus was blown from the lungs through an indiarubber tube, and with a little practice there was no difficulty in maintaining a sufficiently constant blast of the requistte duration. The most suitable pressure was determined by preliminary trials, and was measured by a column of water $9 \frac{1}{2}$ centimetres high.

The first point to be determined was the distance from the source to which the sound remained clearly audible. The experiment was tried in the middle of a fine still winter's day, and it was ascertained that the whistle was heard without effort at a distance of 820 metres. In order to guard against any effect of wivd, the precaution was taken of repeating the observation with the direction of propagation reversed, but without any difference being observable.

The only remaining datum necessary for the calculation is the quantity of air which passes through the whistle in a given time. This was determined by a laboratory experiment. The indiarubber tube was put into connection wit' the interior of a rather large bell-glass open at the bottom, and this was pressed gradually down into a large vessel of water in such a manner that the manometer indicated a steady pressure of $9^{\frac{1}{2}}$ centimetres. The capacity of the bell-glass was 5,200 cubic centimetres, and it was found that the supply of air was sufficient to last $26 \frac{1}{2}$ seconds of time. The consumption of air was therefore 196 cubic centimetres per second. 